Article

\title{
Triple-Layer Nanocomposite Membrane Prepared by Electrospinning Based on Modified PES with Carbon Nanotubes for Membrane Distillation Applications
}

\author{
Mohamed R. Elmarghany 1,2,3, Ahmed H. El-Shazly ${ }^{2,4}$, Saeid Rajabzadeh ${ }^{3}$ (D), \\ Mohamed S. Salem 1,2,3, Mahmoud A. Shouman 1,2, Mohamed Nabil Sabry 1,5, \\ Hideto Matsuyama ${ }^{3, *}$ and Norhan Nady ${ }^{6, *(D)}$ \\ 1 Mechanical Power Engineering Department, Faculty of Engineering, Mansoura University, Mansoura 35516, \\ Egypt; Mohamed_ragab@mans.edu.eg (M.R.E.); Mohamedsameh@mans.edu.eg (M.S.S.); \\ m_shouman@mans.edu.eg (M.A.S.); Mnabil.sabry@gmail.com (M.N.S.) \\ 2 Chemical and Petrochemicals Engineering Department, Egypt-Japan University of Science and \\ Technology (E-JUST), Alexandria 21934, Egypt; elshazly_a@yahoo.com \\ 3 Research Center for Membrane and Film Technology, Department of Chemical Science and Engineering, \\ Kobe University, Rokkodaicho 1-1, Nada, Kobe 657-8501, Japan; rajabzadehsaeid@gmail.com \\ 4 Chemical Engineering Department, Faculty of Engineering, Alexandria University, Alexandria 21544, Egypt \\ 5 Nanotechnology Center, Mansoura University, Mansoura 35516, Egypt \\ 6 Polymeric Materials Research Department, City of Scientific Research and Technological \\ Applications (SRTA-City), Borg El-Arab City, Alexandria 21934, Egypt \\ * Correspondence: matuyama@kobe-u.ac.jp or hmatsuyama411@gmail.com (H.M.); \\ Norhan.nady77@yahoo.com (N.N.)
}

Received: 30 November 2019; Accepted: 14 January 2020; Published: 16 January 2020

\begin{abstract}
In this work, a novel triple-layer nanocomposite membrane prepared with polyethersulfone (PES)/carbon nanotubes (CNTs) as the primary bulk material and poly (vinylidene fluoride-cohexafluoro propylene) $(\mathrm{PcH}) / \mathrm{CNTs}$ as the outer and inner surfaces of the membrane by using electrospinning method is introduced. Modified PES with CNTs was chosen as the bulk material of the triple-layer membrane to obtain a high porosity membrane. Both the upper and lower surfaces of the triple-layer membrane were coated with $\mathrm{PcH} / \mathrm{CNTs}$ using electrospinning to get a triple-layer membrane with high total porosity and noticeable surface hydrophobicity. Combining both characteristics, next to an acceptable bulk hydrophobicity, resulted in a compelling membrane for membrane distillation (MD) applications. The prepared membrane was utilized in a direct contact MD system, and its performance was evaluated in different salt solution concentrations, feed velocities and feed solution temperatures. The results of the prepared membrane in this study were compared to those reported in previously published papers. Based on the evaluated membrane performance, the triple-layer nanocomposite membrane can be considered as a potential alternative with reasonable cost, relative to other MD membranes.
\end{abstract}

Keywords: membrane distillation; water desalination; polyethersulfone; three-layer nanocomposite membrane

\section{Introduction}

Water is an unlimited renewable resource that is distributed on earth in liquid, solid, and vapor forms through a closed cycle (cyclo-hydrological) powered by the energy of the sun. Without water, no life on our blue planet is possible. Only 3\% of all the water on the earth is available as potable water [1]. Furthermore, the need for freshwater has visibly increased during the past few years all 
over the world [2]. Desalination, which is a process of removing the salts present in water, represents the primary alternative source for freshwater. Typical thermal-based desalination techniques use intense energy and require considerable space and expensive equipment. Therefore, membrane-based desalination processes are preferred [3].

Membrane Distillation (MD) is a membrane-based separation technique that uses a hydrophobic porous membrane to separate warm saline feed and cold desalted condensate [4,5]. The membrane allows water vapor to pass through its pores due to the difference in vapor pressure across its sides. Hydrophobicity of the membrane retains liquid water from entering the membrane pores and flowing through its bulk structure. MD configurations include vacuum membrane distillation, sweeping gas membrane distillation, air gap membrane distillation, and direct contact membrane distillation [5].

MD exhibits many advantages over the conventional desalination techniques [6-8] such as lower energy consumption than that the multi-stage flash distillation, lower working pressure than that the Reverse Osmosis ( $\mathrm{RO}$ ) processes, low fouling phenomena compared to the RO desalination process [9-11] and almost 100\% salt rejection. One of the major factors hindering MD development is the existence of membranes with a reasonable cost $[12,13]$. The commercial membranes that are suitable for MD are made of different polymers such as poly (vinylidene fluoride-co-hexafluoropropylene) $(\mathrm{PcH})$, polytetrafluoroethylene (PTFE), polyvinylidene fluoride (PVDF), and polypropylene (PP) [14,15]. Although these polymers are hydrophobic by nature, which resulted in somehow high membrane performance by avoiding membrane wetting or capillary condensation during the water desalination, usually, they are expensive. Recently, more consideration has been given to investigate appropriate membrane materials suitable for the MD process to enhance the MD membrane durability for long-term applications by improving the membrane hydrophobicity $[16,17]$.

One of the main techniques commonly used to enhance the membrane properties to be suitable for the MD process is blending with different nano-additives [18-20]. For example, the immense potential of carbon nanotubes (CNTs) as an additive has been a subject of interest to be used in the fabrication of the membranes [21,22]. Both single-walled carbon nanotubes (SWCNTs) and multi-walled carbon nanotubes (MWCNTs) have been included in different polymeric membranes to enhance their hydrophobicity $[23,24]$. SWCNTs have better properties than MWCNTs, but difficult dispersion is a noticeable issue. In addition to the known eminent hydrophobicity of the CNTs, the inclusion of CNTs increases the membrane surface roughness, which enhances the membrane surface hydrophobicity, a critical property for many MD applications [25-28].

Moreover, functionalized forms of CNTs have been used as an immobilized agent in the membrane for enhancing the membrane mechanical and thermal properties [29,30]. Also, modified graphene and graphene oxide (GO) as an additive used in the MD membrane preparation give a unique structure with superior mechanical stiffness, thermal stability, and considerable reduction in temperature polarization [31]. Hydrophobic nature, low cost, liquid water permeability, selective sorption of water vapors, and anti-fouling properties make modified graphene and graphene oxide membranes attractive for MD applications [32].

It is noteworthy that some polymers such as tetrafluoroethylene and hexafluoropropylene have recently attracted attention as a potential membrane material used for MD rather than PVDF due to the increased fluorine content resulting in higher hydrophobicity than the PVDF [31]. Similarly, poly (vinylidene fluoride-co-hexafluoropropylene) $(\mathrm{PcH})$ [33] and poly (vinylidene fluoride-cotetrafluoroethylene) (PVDF-TFE) [34] polymers are potential candidates for MD applications since the hydrophobicity of these membrane materials are remarkable (i.e., water contact angle $>154^{\circ}$ ).

Polyethersulfone (PES) is a vastly used polymer in the fabrication of microfiltration and ultrafiltration membranes [35,36]. It has many advantages compared to other polymers such as high thermo-plasticity, excellent mechanical properties, perfect chemical, and thermal stability at elevated temperatures, relatively higher transition temperature, and lower cost than other membrane materials that have been used for MD process [37-39]. Despite all the advantages of PES as membrane material, it is difficult to use this material for producing MD membranes because its hydrophobicity is 
relatively low. Composite PES membranes utilizing titanium oxide nanotubes as additives have been fabricated and used for vacuum membrane distillation and led to the formation of a highly dense layer of titanium dioxide on the membrane surface [40].

Electrospinning of polymer nanofibers has attracted considerable attention over the past decade as a direct and straightforward method of obtaining nanostructures for different applications [41]. The rapidly developing electrospinning technique is a unique way of getting new polymer nanofibers with a diameter, usually in the range of $50 \mathrm{~nm}$ to $500 \mathrm{~nm}$. In the electrospinning method, a solution in which a material is dissolved in a solvent is used as a spinning material. There are some parameters related to the electrospinning, which can affect the morphology of the prepared nanofibers, and they are divided into three groups: solution characteristics, spinning environment, and spinning conditions [5,42,43]. Electrospinning with and without multi-nozzle systems have been used to fabricate nanofiber membranes for the applications of MD [33,44]. Electrospun nanofibers have been obtained using many hydrophobic polymers such as PVDF and PcH [45-47]. Compared to other known membrane fabrication methods such as phase separation, electro-spun membranes have unique characteristics such as small fiber diameter, high specific surface area, and high porosity [48].

To date, PES has rarely been applied for MD applications, as it is not inherently hydrophobic, although it has been widely used in porous membranes (MF and UF) preparation. Few studies investigated the utilization of phase-inversion-coated PES membranes in MD [49,50].

In this study, cost-effective material such as PES was used to prepare the bulk of the membrane by blending a tiny percentage $(0.5 \%)$ of CNTs in its dope to obtain high porosity as well as acceptable hydrophobicity. Our initial evaluations showed that using only PES/CNTs as the membrane for MD applications is not suitable considering low liquid entry pressure (LEP), which means the membrane can be easily wetted by the feed solution. Electro-spun prepared PES/CNTs membrane was sandwiched between two layers of the PcH/CNTs as skin layers at both sides of the membrane bulk (top and bottom surfaces) to increase the MD performance by avoiding membrane wetting based on the increase in surface hydrophobicity and LEP. It was concluded that the product of the method used in this study combines the high total porosity of the membrane with high hydrophobicity and LEP of the membrane surface. The prepared MD membranes (Control PES/CNTs and PcH/CNTs and also triple-layer nanocomposite membrane) performance in terms of membrane water flux and salt rejection was determined for the desalting process by simulated saline water, and results were compared with those of the membranes prepared in similar studies.

\section{Materials and Methods}

\subsection{Materials}

Polyethersulfone (PES) Ultrason E 6020P (glass transition temperature of $\mathrm{Tg}=225^{\circ} \mathrm{C}$ and a molecular weight of 58,000 g/mol) was obtained from BASF chemical company (Ludwigshafen, Germany). Poly (vinylidene fluoride-co-hexafluoropropylene) $(\mathrm{PcH})$ in pellets form (glass transition temperature of $\mathrm{Tg}=140{ }^{\circ} \mathrm{C}$, density $=1.78 \mathrm{~g} / \mathrm{mL}$ at $25^{\circ} \mathrm{C}$ ) was supplied by Sigma-Aldrich. 1-Methyl-2Pyrrolidone (NMP) (>99\% C5H9NO, and density of $1.028 \mathrm{~g} / \mathrm{mL}$ ) was purchased from CHEM-LAB, Belgium. N, N-Dimethylformamide (DMF) (HPLC grade, $99.8 \%$ and density of $1.4305 \mathrm{~g} / \mathrm{mL}$ ), N, N-dimethylacetamide (DMAc) (ACS, $>99 \%$ and density of $0.937 \mathrm{~g} / \mathrm{mL}$ ) and acetone (HPLC grade, $>99.9 \%$ ) were purchased from DOP ORGANIK KIMYA (Turkey). Multi-walled carbon nanotubes (MWCNTs) (>90\% carbon basis, a diameter of $110-170 \mathrm{~nm}$, length of 5-9 $\mu \mathrm{m}$ and density of $1.7 \mathrm{~g} / \mathrm{L}$ ) were supplied by Sigma-Aldrich and used as it is.

\subsection{Membrane Preparation}

Triple-layer nanocomposite layer, as well as control membranes (pure PES and pure PcH), were prepared and their MD performance was investigated with the procedure mentioned as follows. A schematic diagram of the prepared membranes is shown in Figure 1. The CNTs content varied from 
0.1 to $1 \mathrm{wt} . \%$, and based on the optimal measured contact angles, $0.5 \%$ CNTs were chosen for the rest of the studies as this percentage results in high mechanical strength and hydrophobicity. The PES/CNTs solutions were prepared as follows: $0.5 \mathrm{wt}$. \% multi-walled CNTs were dispersed in NMP: DMF solvent (volume ratio 1:9) by sonication (LABSONIC, model: LBS2 4.5 Lt, Falc Instruments, Treviglio, Italy) for $1 \mathrm{~h}$. PES (23 wt.\%) was added to the previously prepared suspension and kept under continuous stirring at $500 \mathrm{rpm}$ for $12 \mathrm{~h}$ at $60^{\circ} \mathrm{C}$. Ultrasonic degassing for the dope solution was done for $1 \mathrm{~h}$ at room temperature $\left(25 \pm 2{ }^{\circ} \mathrm{C}\right)$. The pure PES membrane was prepared in the same manner but without adding multi-walled CNTs. Electrospinning was performed in the nanofiber electrospinning system (NANON-01A, Mecc Co., Ltd., Fukuoka, Japan). In the present study, the solution was first fed to the syringe (12.3 mm inner diameter), and a stainless-steel needle (OD: $0.9 \mathrm{~mm}$, ID: $0.6 \mathrm{~mm}$ ) was used. The distance between the needle tip and the collector was kept at $15 \mathrm{~cm}$, an electric voltage of $20 \mathrm{kV}$ was applied with a spinneret speed and width of $50 \mathrm{~mm} / \mathrm{s}$ and $120 \mathrm{~mm}$, respectively. The flow rate of the polymeric solutions was constant throughout the study at $1 \mathrm{cc} / \mathrm{h}$, and the electrospinning time was $5 \mathrm{~h}$. After that, the prepared membranes were put in an oven at $60{ }^{\circ} \mathrm{C}$ for $24 \mathrm{~h}$ to remove the residuals of the solvents. For the preparation of the PcH/CNTs membrane, $0.5 \mathrm{wt} . \%$ multi-walled CNTs were dispersed in the prepared mixture of solvents (DMAc: Acetone $=20: 80 \mathrm{vol}$. \%) by sonication for $1 \mathrm{~h}$. $\mathrm{PcH}(15 \mathrm{wt} . \%)$ was added to the suspension and kept under continuous stirring at $500 \mathrm{rpm}$ for $12 \mathrm{~h}$. After that, ultrasonic degassing was done for $1 \mathrm{~h}$ for the solution at room temperature $\left(25 \pm 2{ }^{\circ} \mathrm{C}\right)$ before the electrospinning. Electrospinning was at $22 \mathrm{kV}$ and feed rate of $1.2 \mathrm{cc} / \mathrm{h}$ with the same previous parameters. After electrospinning, the membrane was put in the oven at $60^{\circ} \mathrm{C}$ for 1 day to remove the solvent residuals. The pure $\mathrm{PcH}$ membrane was prepared in the same manner but without adding the multi-walled CNTs. To prepare the triple-layer nanocomposite membrane, the previously prepared dope for each polymer was used as the same with $0.5 \mathrm{wt}$ \% CNTs additive. During the electrospinning, a thin layer of $\mathrm{PcH}$ was prepared using $0.75 \mathrm{cc}$ dope as an electrospun solution, followed by a thick layer of PES preparation using a 4-cc dope solution. Then, another thin layer of PcH was electrospun over the PES layer with the procedure mentioned above, and after that, the prepared membrane was kept at $60{ }^{\circ} \mathrm{C}$ for $24 \mathrm{~h}$. The coded names of the prepared membranes with their composition of each prepared membrane are summarized in Table 1.

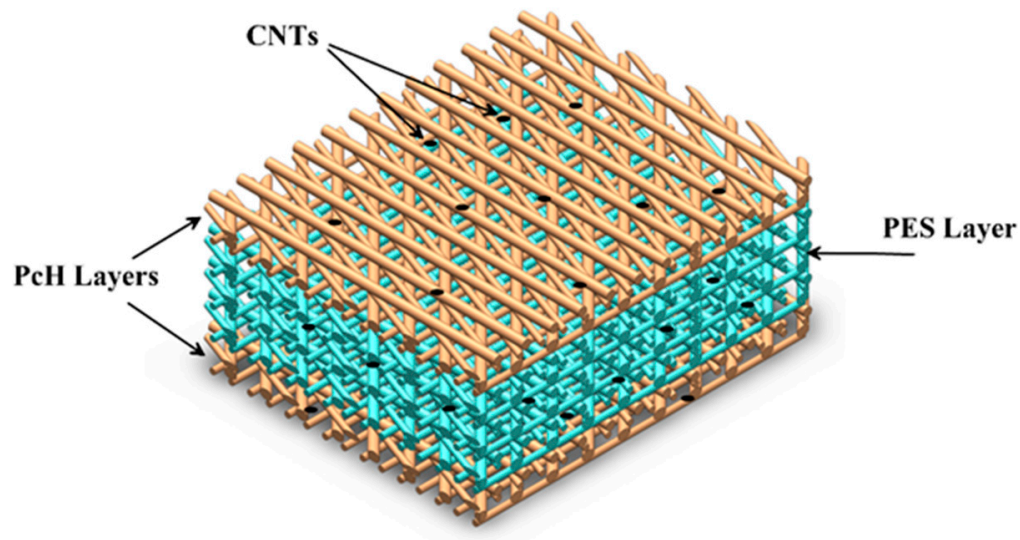

Figure 1. Schematic of the prepared triple-layer nanocomposite membrane.

Table 1. Codes and compositions of the prepared membranes.

\begin{tabular}{cccc}
\hline Membrane Code & PES wt. $\%$ & PcH wt. $\%$ & CNTs wt. $\%$ \\
\hline PES & 23 & - & - \\
PcH & - & 15 & - \\
PES/CNTs & 23 & - & 0.5 \\
PcH/CNTs & - & 15 & 0.5 \\
PcH-PES-PcH/CNTs & 23 & 15 & 0.5 \\
\hline
\end{tabular}




\subsection{Membrane Characterization}

\subsubsection{Membrane and Nanofiber Morphology}

Transmission electron microscopy (TEM, 2100Plus, JEOL Ltd., Tokyo, Japan) was used to observe the distribution of the CNTs in the prepared membranes. The membrane cross-section sample was cut by using PowerTom Ultramicrotomes (RMS Boeckeler, Boeckeler Instruments Inc., Tucson, Arizona, USA) after hardness in Araldite ${ }^{\circledR}$ Embedding Resin (Mollenhauer, Germany). Scanning electron microscopy (SEM) (JCM-6000PLUS NeoScope Benchtop SEM, JEOL Ltd., Tokyo, Japan) was used to examine the morphology of the surfaces of the fabricated membranes and to calculate the average diameter of the nanofibers of each membrane. SEM images for all prepared membranes were taken after coating the samples with Platinum/Palladium alloy.

\subsubsection{Liquid Entry Pressure (LEP)}

Liquid entry pressure (LEP) of each membrane was examined using a simple test set, as shown in Figure 2. The membrane was placed in a special cell equipped with a pressure gauge, and a chamber was filled up with distilled water. The chamber was connected to an air cylinder by a throttling valve, which was used to gradually increase the air pressure over the free surface of distilled water. LEP was reported by starting with low pressure which was slightly increased until the liquid water penetrates the membrane.

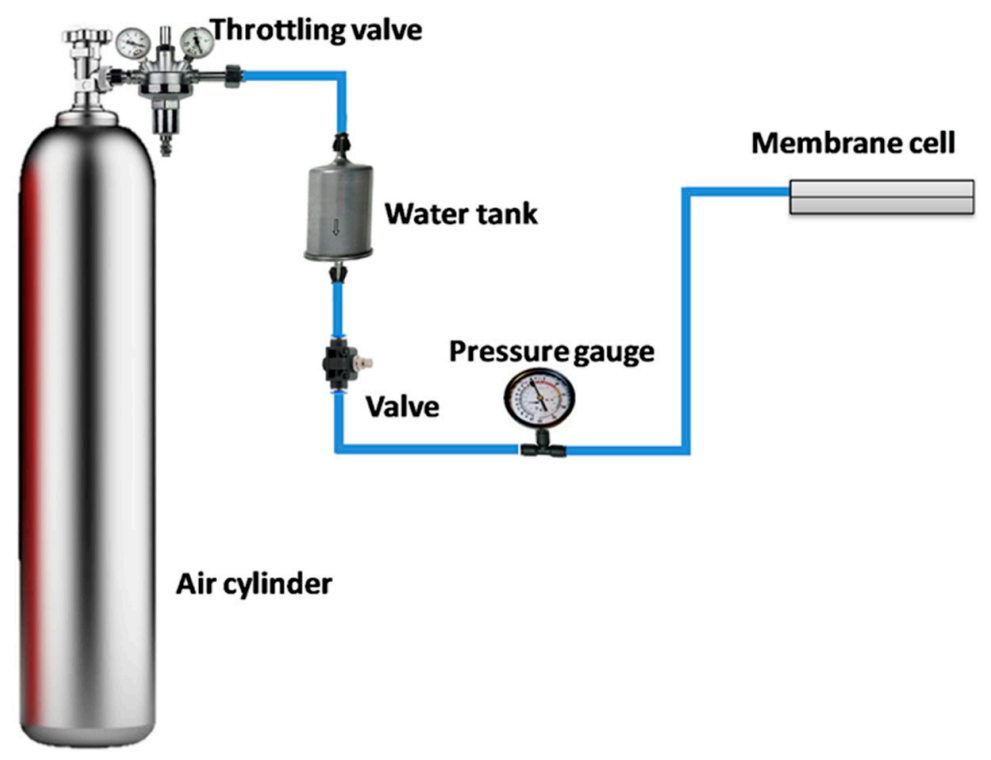

Figure 2. The liquid entry pressure investigation set up.

\subsubsection{Membrane Morphology}

The porosity $(\varepsilon)$ of the fabricated membranes was obtained by measuring the wet and dry weights of the membrane samples. The wet weight of the membrane sample was measured after immersing it in ethanol for $10 \mathrm{~min}$. After drying the sample, the dry weight of the sample was measured. The membrane porosity was determined using the following equation [46]:

$$
\varepsilon=\frac{\frac{m_{w}-m_{d}}{\rho_{e}}}{\left[\frac{m_{w}-m_{d}}{\rho_{e}}\right]+\frac{m_{d}}{\rho_{P}}}
$$

where $m_{w}$ is the wet membrane weight $(\mathrm{g}), m_{d}$ is the dry membrane weight $(\mathrm{g}), \rho_{e}$ is the density of ethanol $\left(\mathrm{g} / \mathrm{cm}^{3}\right)$ and $\rho_{P}$ is the density of the polymer or determined density of polymer/CNTs composite material $\left(\mathrm{g} / \mathrm{cm}^{3}\right)$. 
ImageJ software was used to investigate the average pore size and the average fiber diameter of the prepared membranes [25,51,52]. In total, 400 pores were considered using SEM images to determine the average pore diameter of the membranes using image processing.

\subsubsection{Static Water Contact Angle}

Contact angle measuring device (Drop Shape Analyzer-DSA100, KRÜSS GmbH, Hamburg, Germany) was used to determine the water contact angle for membranes samples. A water droplet of four microns was dropped over the surface of each membrane and was analyzed using the captured images. The reported value was the average of six readings on two different samples for each membrane.

\subsubsection{Membrane Thickness}

The average membrane thickness was obtained through five measurements at different points on each membrane sample using a micrometer (range: 0-25 mm, precision: $2 \mu \mathrm{m}$, HDT, China).

\subsection{Membrane Distillation (MD) Cell Design}

The MD cell used in this study is a flat sheet design cell that was entirely fabricated at the workshops of Egypt-Japan University of Science and Technology (E-JUST). The cell consists of two identical parts made of aluminum sheets, as shown in Figure 3. The gross dimensions of the cell are $90 \mathrm{~mm}$ length by $90 \mathrm{~mm}$ width with a total height of $22 \mathrm{~mm}$ and inlet and outlet diameters of $6 \mathrm{~mm}$ for each part. The effective area of the membrane is $20.25 \mathrm{~cm}^{2}$, and the depth of the flow is about $2 \mathrm{~mm}$. Rubber gaskets and membrane spacers (around $1.5 \mathrm{~mm} \times 1.5 \mathrm{~mm}$ square pore size) are placed at each side of the membrane to avoid water leakage and to support the membrane, respectively.

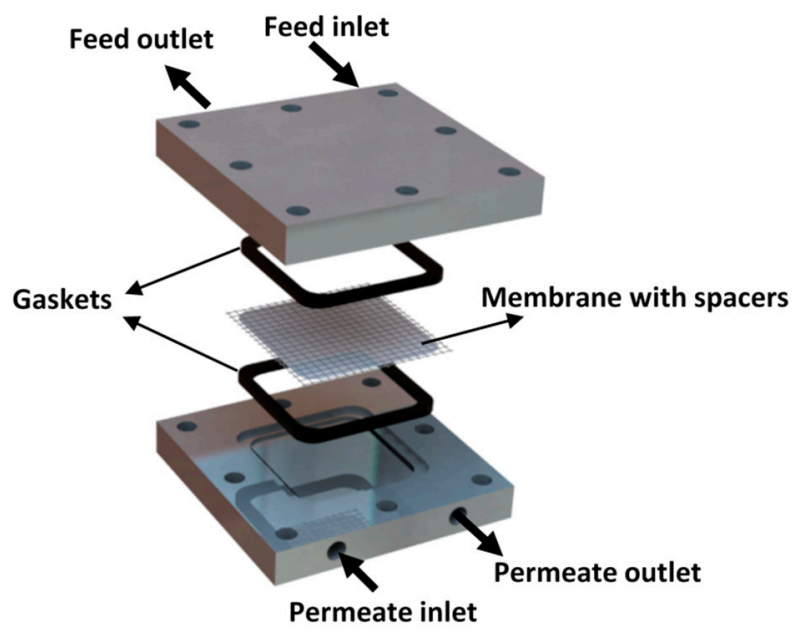

Figure 3. Schematic diagram of the fabricated membrane distillation (MD) cell.

\subsection{Membrane Distillation Experiments}

All direct contact MD experiments were conducted in a laboratory-scale experimental test rig consisting of a continuous hot loop at the feed side and a continuous lukewarm loop at the permeate side, as shown in Figure 4. The hot loop was heated via a water bath (type: SB-1000, Cole-Parmer, Tokyo RIKAKIKAI co., LTD) and circulated using a micro-pump (Micropump L20561 A-Mount Suction Shoe Pump Head; Cole-Parmer, USA). The permeate side consists of a micro gear pump (model: WT3000-1JB, Longer precision pump Co., Ltd. Baoding, China), a storage tank, and a weighing machine (model: 1177 BKWHDR, Resolution: 1 g, Salter Leaf Electronic Digital Scale, FKA Brands Ltd., Tonbridge, Kent, United Kingdom). The permeate side was kept at a constant temperature using a thermostatic bath in circulator mode (LAUDA Alpha RA 8, LAUDA-Brinkmann, LP, Delran, NJ, USA). 


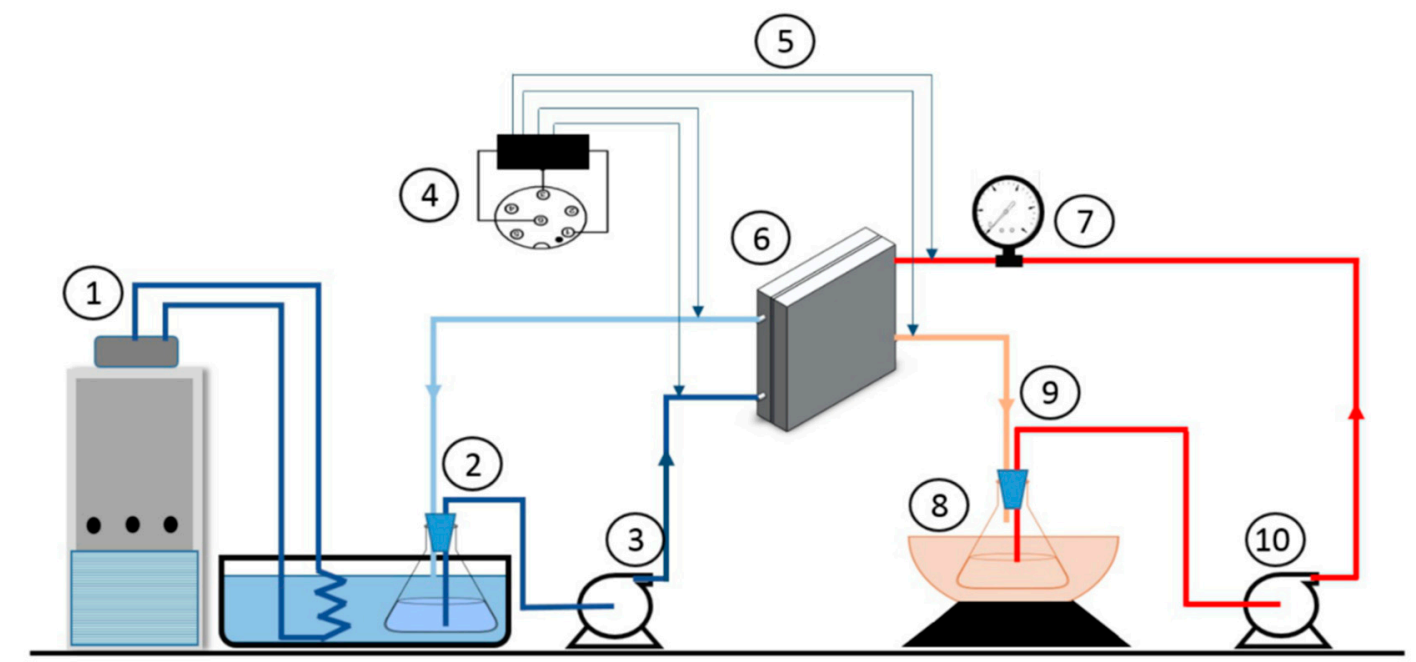

(a)

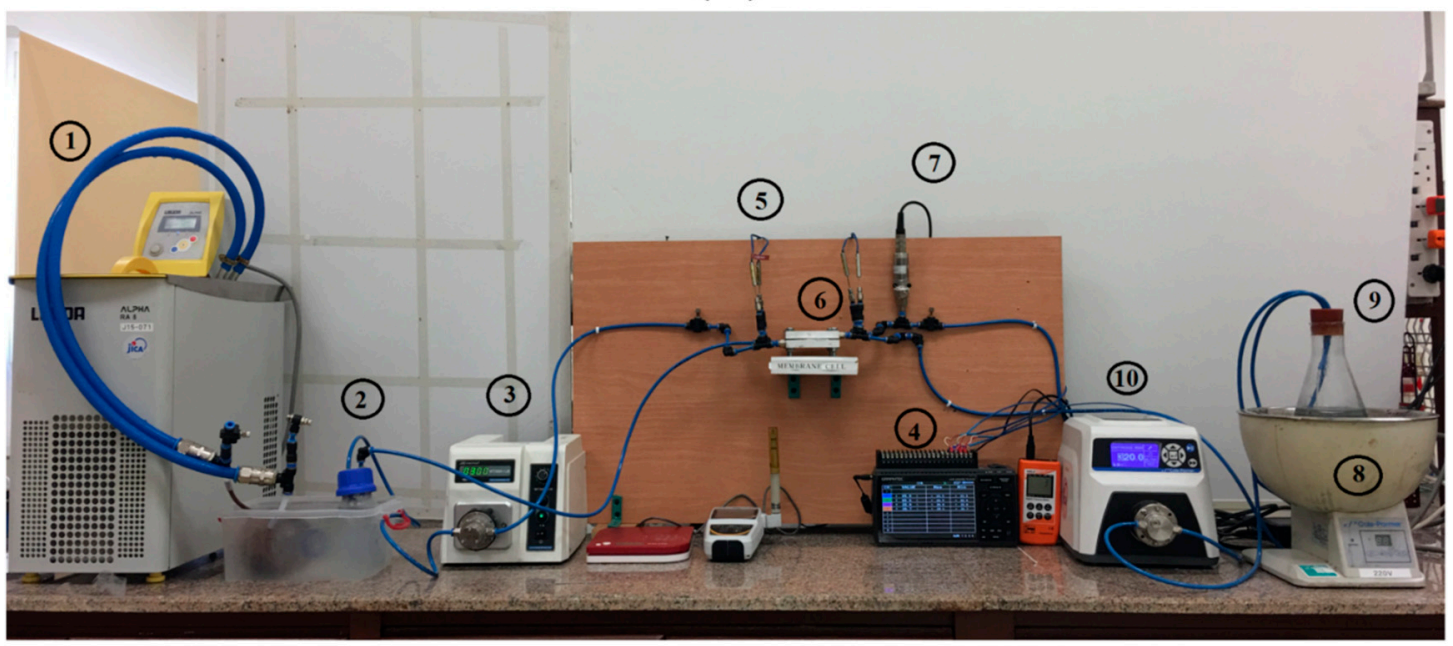

\section{(b)}

Figure 4. (a) Schematic diagram and (b) Photo of the used experimental test setup: 1. Thermostatic bath equipped with circulator, 2 . Permeate flask, 3. Permeate pump, 4. Data logger, 5. Thermocouples, 6. MD Cell, 7. Pressure meter, 8. Heating bath, 9. Feed flask, and 10. Feed pump.

All flow rates were monitored and recorded during the test. The pressure was measured using a pressure meter (HND-P Series, KOBOLD Instruments Inc, Pittsburgh, PA, USA). Feed inlet and outlet temperatures and permeate inlet and outlet temperatures were measured using k-type thermocouples (model: TSK, JUST CO., LTD., Komaki, Japan) and was recorded using an isolated standalone multi-channel datalogger (midi LOGGER GL840, Graphtec Corporation, Yokohama, Japan). Waterproof conductivity meter (CON 150, Eutech Instruments Pte Ltd, Paisley, Scotland) was used to record the total dissolved salts (TDS) and the water conductivity. The feed and permeate flow rates were monitored and directly recorded.

\section{Results and Discussion}

\subsection{Optimal Concentration of the Carbon Nanotubes Content}

As mentioned in Section 2.2, different CNTs concentrations were used for the preparation of PES/CNTs membranes with percentage of $0.1,0.3,0.5,0.7$, and 1 wt.\% respectively. Homogenous dispersion of the CNTs in the membrane polymer matrix and hydrophobicity of the prepared 
membranes were considered as the two crucial criteria to predict the enhancement in performance of the prepared membrane to select the membrane CNTs content accordingly. Figure 5 shows that by increasing the CNTs percentage to $0.5 \mathrm{wt} . \%$, the static water contact angle reached a maximum value of $128^{\circ}$, and with further increase in CNTs content contact angle decreased slightly to $125^{\circ}$. This phenomenon can be explained as follows. Higher addition of CNTs content resulted in aggregations which consequently resulted in lowering the contact angle, as well as the poor distribution of the CNTs in the polymer matrix. Therefore, $0.5 \mathrm{wt}$. \% of CNTs were chosen as the additive optimal percentage for all membranes. It is important to mention that although adding CNTs pronounce the thermal conductivity and consequently the thermal polarization since in this study a very small percentage was used (about $0.5 \%$ ), authors think that the effect of the thermal polarization related to the presence of the CNTs won't be noticeable.

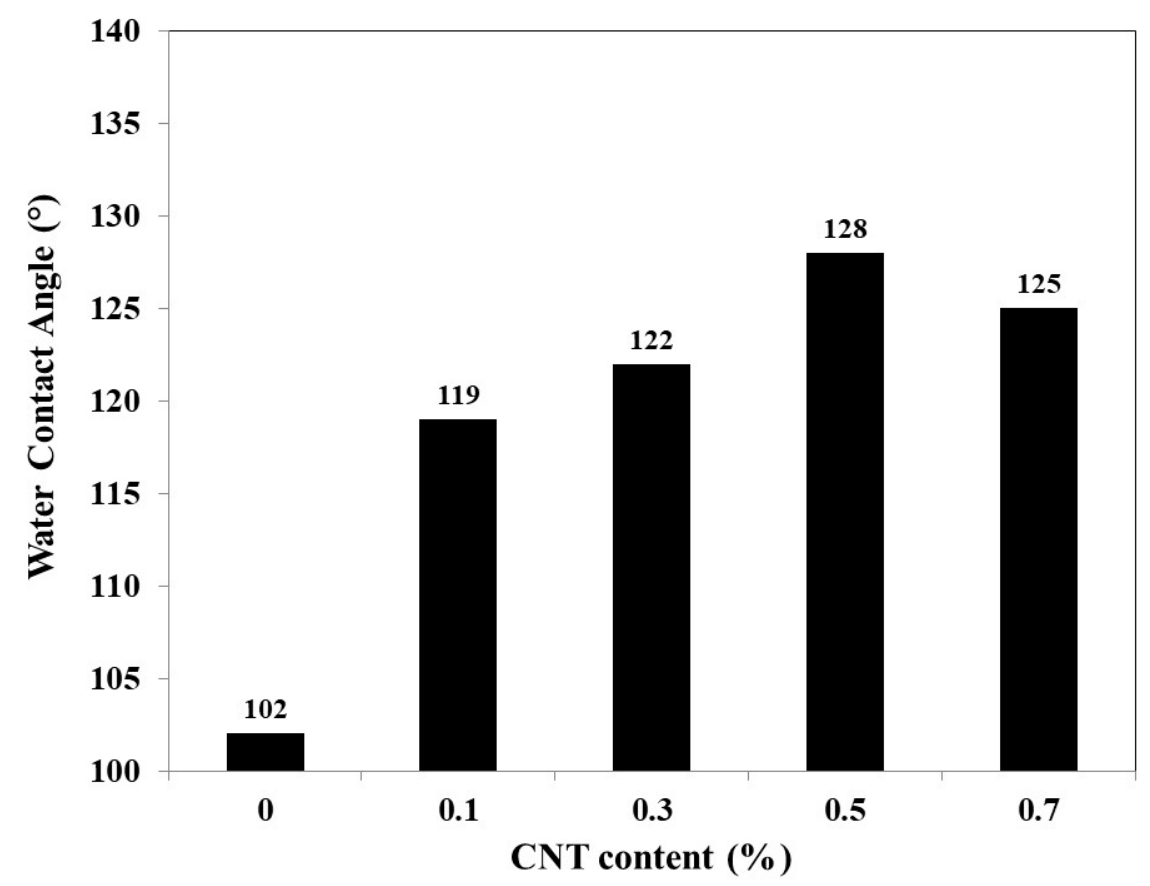

Figure 5. Contact angle measurements.

\subsection{Membrane Characterization}

\subsubsection{SEM and TEM Observation}

Based on the SEM surface images of the different prepared membranes shown in Figure 6, almost uniform fiber diameters and smooth surfaces were fabricated. The low content of CNTs in the membrane dope composition and sonication of CNTs in the organic solvent led to appropriate distribution of the nanoparticles and prevented CNTs aggregation. These results are in line with the findings of Luong [53]. The diameter of CNTs $(110-170 \mathrm{~nm})$ is much thinner than those of membranes nanofibers. Thus, the CNTs seem to be coated by the polymer. ImageJ software was used to estimate the average fiber diameter. The fiber diameters in five membranes were almost the same around $347 \mathrm{~nm}$ with a maximum $5 \%$ deviation that is believed as an experimental error for different dope solutions. Thus, it can be concluded that the fiber diameters were mainly affected by the electrospinning process parameters rather than the membrane composition. 

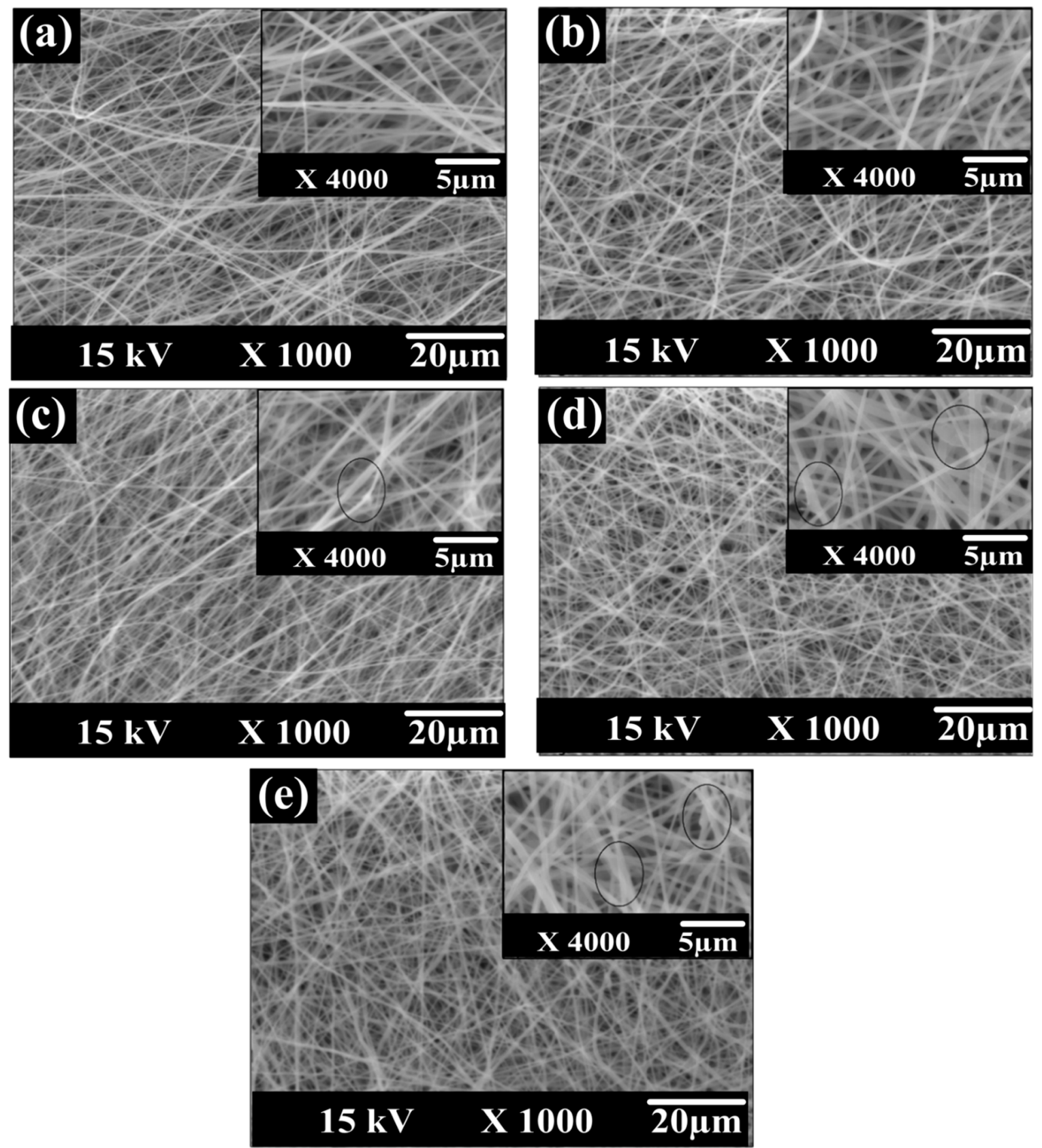

Figure 6. SEM images for the prepared membranes surface: (a) pure polyethersulfone (PES), (b) PES/carbon nanotubes (CNTs), (c) Pure poly (vinylidene fluoride-co-hexafluoro propylene (PcH), (d) $\mathrm{PcH} / \mathrm{CNTs}$, and (e) triple-layer PcH-PES-PcH/CNTs nanocomposite membranes.

As shown in Figure 7, TEM images for the triple-layer PcH-PES-PcH/CNTs nanocomposite membrane were shown at two different magnifications. Figure 7a shows the homogenous distribution of the CNTs in the membrane matrix. Using higher magnification of the TEM, CNTs were observed in the membrane nanofiber membranes. 

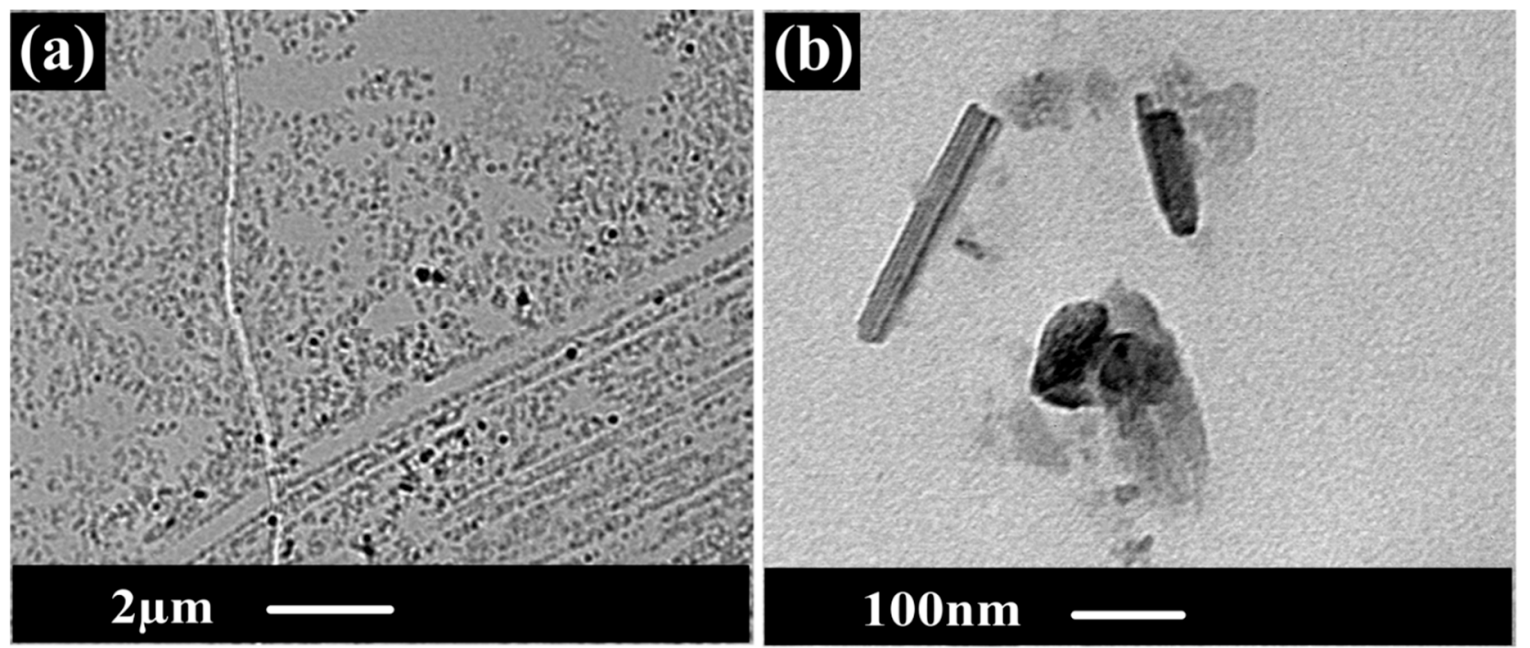

Figure 7. TEM cross-section images for the PcH-PES-PcH/CNTs membrane at different scales. (a) shows the homogenous distribution of CNTs; (b) the average size of CNTs.

\subsubsection{Water Contact Angle Measurement}

As shown in Figure 8, while pure PES membrane showed the lowest contact angle of $92^{\circ} \pm 1.7^{\circ}$ (Figure 8a), pure $\mathrm{PcH}$ membrane contact angle was $119^{\circ} \pm 1.8^{\circ}$ (Figure $8 \mathrm{c}$ ). By adding CNTs to PES, the contact angle increased to $128^{\circ} \pm 1.5^{\circ}$ (Figure $8 \mathrm{~b}$ ), which is higher than pure $\mathrm{PCH}$. As it was strongly expected, both PcH/CNTs and triple-layer PcH-PES-PcH/CNTs nanocomposite membranes showed a similar surface contact angle of $144^{\circ} \pm 2^{\circ}$ (Figure $8 \mathrm{~d}$ ), because the PES/CNTs layer is sandwiched between two layers of the $\mathrm{PcH} / \mathrm{CNTs}$. Higher hydrophobicity (higher contact angle values) is directly related to the presence of CNTs, which was proven to exhibit high hydrophobicity [54]. It is worth mentioning that besides the hydrophobic nature of the CNTs particles, the presence of the CNTs increased the surface roughness which resulted in an increase in hydrophobicity. This is in full agreement with the relationship between roughness and wettability which had been already defined in 1936 by Wenzel [55]. In other words, if the surface is chemically hydrophobic, increasing the surface roughness makes the surface more hydrophobic. For MD applications, it is crucial to create high surface hydrophobicity to avoid membrane wetting, which is the main drawback that sharply decreases the membrane performance. Meanwhile, the hydrophilicity of the membrane bulk material is also a matter of importance to avoid the capillary condensation phenomenon (i.e., avoiding the possibility of water vapor condensation inside the membrane pores structure) that can decrease the MD membrane performance as well [56]. Contact angle results of the triple-layer nanocomposite membrane show noticeably high surface hydrophobicity (water contact angle of $144^{\circ} \pm 2^{\circ}$ ) with appropriate membrane bulk hydrophobicity, which is expected to be similar to of PES/CNTs. Thus, considering the hydrophobicity of the prepared membrane, it is expected that the triple-layer nanocomposite membrane would be potentially suitable for MD applications. 


\section{(a)}

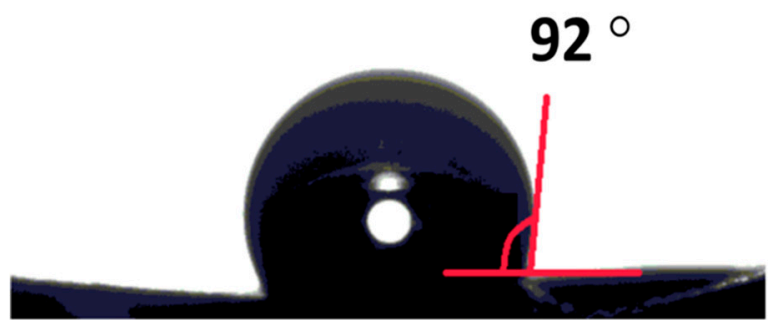

(b)
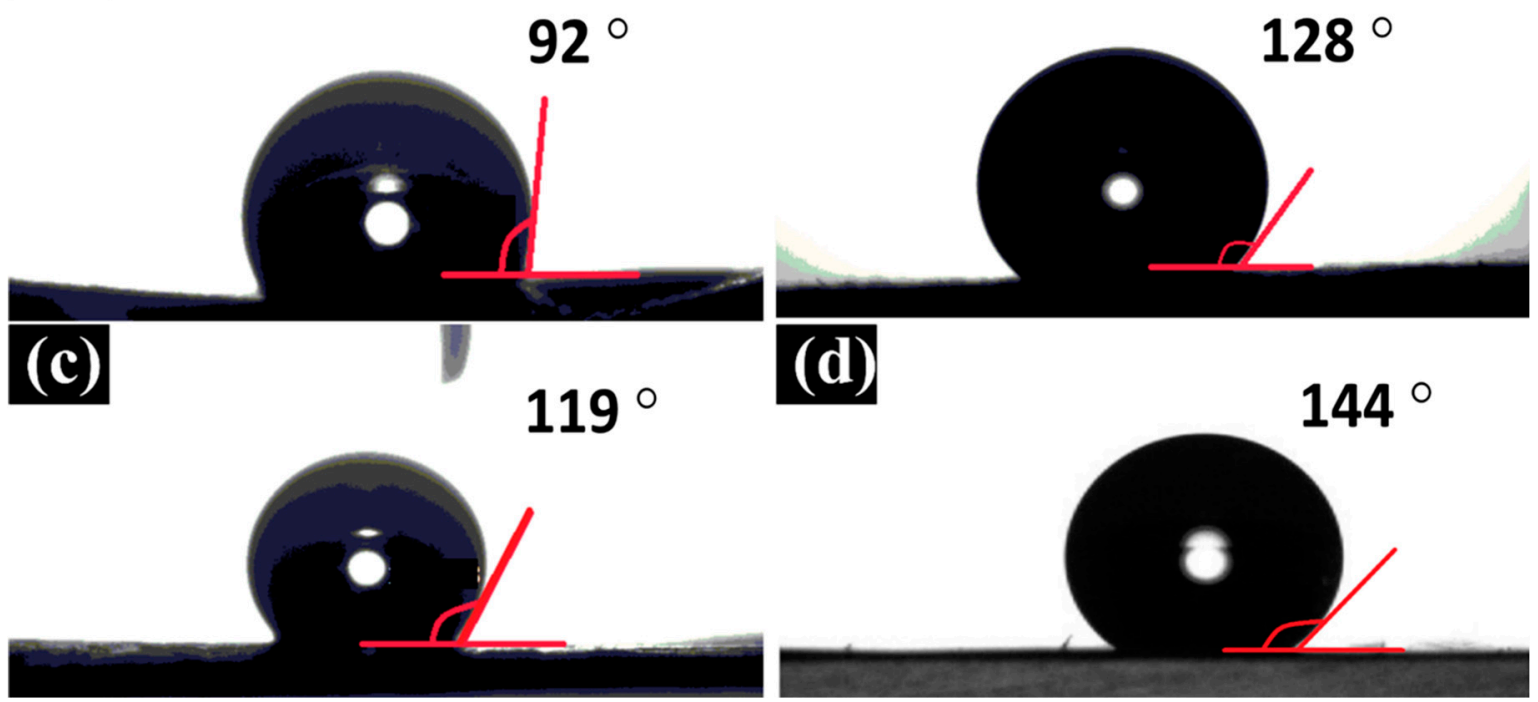

Figure 8. Contact angle results for (a) pure PES, (b) pure PcH, (c) PES/CNTs, and (d) PcH-PES-PcH/CNTs, which is almost the same as $\mathrm{PcH} / \mathrm{CNTs}$.

\subsubsection{Membrane Thickness, Porosity, LEP, and Average Fiber and Pore Diameters Measurements}

Prepared membranes were characterized in terms of their thickness, porosity, LEP, and average fiber and pore diameters. The results were tabulated in Table 2. The thicknesses of the membranes were hardly changed with different polymeric solution compositions. However, we can notice that adding CNTs to the pure polymers resulted in a slight reduction in the membrane thickness $(7.1 \%$ reductions in the case of PES/CNTs membrane and $14.8 \%$ in case of $\mathrm{PcH} / \mathrm{CNTs}$ membrane) compared to those of pure PES and pure PcH membranes, respectively. Although a more detailed study is needed, we hypothesize that this decrease in membrane thickness might be related to the excellent conductivity of CNTs, which resulted in higher solution conductivity. This may have increased the attraction forces between the fibers during the electrospinning process, thus resulted in creating thinner layers.

Table 2. Characteristics of different produced membranes include liquid enter pressure (LEP), membrane thickness, membrane porosity, contact angle, and the membrane fiber diameter.

\begin{tabular}{cccccc}
\hline Membrane Code & $\begin{array}{c}\text { Membrane } \\
\text { Thickness }(\boldsymbol{\mu m})\end{array}$ & $\begin{array}{c}\text { Porosity } \\
\boldsymbol{\varepsilon} \mathbf{( \% )}\end{array}$ & $\begin{array}{c}\text { LEP * } \\
\mathbf{( b a r )}\end{array}$ & $\begin{array}{c}\text { Average Fiber } \\
\text { Diameter }(\boldsymbol{\mu m})\end{array}$ & $\begin{array}{c}\text { Average Pore } \\
\text { Diameter }(\boldsymbol{\mu m})\end{array}$ \\
\hline PES & $112 \pm 2.1$ & $92 \pm 1.6$ & NA & $0.342 \pm 0.06$ & $0.79 \pm 0.05$ \\
PcH & $108 \pm 2.3$ & $87 \pm 1.5$ & 1.7 & $0.366 \pm 0.04$ & $0.67 \pm 0.05$ \\
PES/CNTs & $104 \pm 1.9$ & $89 \pm 2.0$ & NA & $0.334 \pm 0.05$ & $0.63 \pm 0.03$ \\
PcH/CNTs & $92 \pm 2.3$ & $86 \pm 2.1$ & 1.8 & $0.338 \pm 0.04$ & $0.56 \pm 0.04$ \\
PcH -PES-PcH/CNTs & $107 \pm 2.8$ & $91 \pm 1.8$ & 1.8 & $0.343 \pm 0.05$ & $0.55 \pm 0.03$ \\
\hline
\end{tabular}

${ }^{*}$ LEP: liquid enter pressure (absolute).

Prepared membranes showed different bulk porosities. High bulk porosity of the prepared membranes is essential for the prepared MD performance [57]. From Table 2, while the pure PES membrane with $92 \pm 1.6 \%$ porosity has the highest porosity among all fabricated membranes, $\mathrm{PcH}$ membranes with or without CNTs showed the lowest porosity of around $86-87 \%$. Although PES/CNTs showed slightly lower porosity than that of PES, the presence of PES in the triple-layer nanocomposite $\mathrm{PcH}-\mathrm{PES}-\mathrm{PcH} / \mathrm{CNTs}$ membrane could positively affect the membrane porosity to be around $(91 \pm 1.8 \%)$. As the higher porosity is suitable to obtain the higher MD performance, the sandwich of the PES layer 
is essential to increase the MD process performance as well as to decrease the material cost of the prepared membrane. The average pore and fiber diameters are reported in Table 2.

The LEPs of different prepared membranes are also summarized in Table 2. For pure PES and PES/CNTs, membranes LEP cannot be recorded because both membranes show breakthroughs of the water at lower detectable limits of the used gauge pressure. It might be concluded from here that electrospun modified PES by CNTs membranes are not appropriate for utilization in the MD processes by themselves, because low LEP resulted in membrane wetting, which drastically decreases the membrane performance. The LEP of PcH-PES-PcH/CNTs nanocomposite membrane is similar to that of the PcH/CNTs membrane. Although the reported LEP in this study is somehow lower than that reported in previous studies, for the application we have considered here, it looks that the 1 bar LEP is adequate. Also, the porosity of PcH-PES-PcH/CNTs composite membrane is adequate (91\%) due to the existence of the middle PES layer with the highest porosity (92\%).

The average fiber and pore diameters and the results were tabulated in Table 2. The results show that, pure PES membrane has the larger average pore diameter and also the added CNTs resulted in reduction in the average pore diameter of both PES/CNTs and $\mathrm{PcH} / \mathrm{CNTs}$ membranes. Meanwhile, both PcH/CNTs and PcH-PES-PcH/CNTs composite membranes show the same average pore diameter around ( 0.55 microns). For the fiber diameter, the fibers are mostly homogeneous for each polymeric membrane, with average diameters of $0.342 \pm 0.06 \mu \mathrm{m}, 0.366 \pm 0.04 \mu \mathrm{m}, 0.334 \pm 0.05 \mu \mathrm{m}, 0.338 \pm 0.04 \mu \mathrm{m}$ and $0.343 \pm 0.05 \mu \mathrm{m}$ for PES, PES/CNTs, PcH, PcH/CNTs, and PcH-PES-PcH/CNTs, respectively. These results show that the fiber diameters were mainly affected by the electrospinning process parameters rather than the membrane composition.

Thus, considering using cost-effective materials such as PES modified with CNTs not only resulted in a considerable reduction in the membrane material cost, but also in an increase of the bulk porosity of the triple-layer nanocomposite membrane, which is necessary for the preparation of an efficient MD membrane.

\subsection{Membrane Distillation Performance Evaluation}

The performance of a direct contact MD system was studied at different feed temperatures, feed flow rates and feed salt concentrations for three different membranes; $\mathrm{PcH}, \mathrm{PcH} / \mathrm{CNTs}$, and PcH-PES-PCH/CNTs.

\subsubsection{Effect of Feed Water Temperature}

The feed water temperature was varied from $35 \pm 1{ }^{\circ} \mathrm{C}$ to $65 \pm 1{ }^{\circ} \mathrm{C}$ by a step of $10{ }^{\circ} \mathrm{C}$, while the feed inlet conditions were kept constant including the flow rate at $27 \mathrm{~L} / \mathrm{h}$ and salt concentration of 10,000 ppm. As shown in Figure 9, increasing the feed temperature increased the membrane flux. This is due to the higher vapor pressure difference between feed and permeates sides according to Antoine equation, which expresses the relationship between the liquid temperature and the corresponding equilibrium vapor pressure. Thus, increasing the driving force for water evaporation enhances membrane permeation flux. Triple-layer nanocomposite PcH-PES-PcH/CNTs membrane showed the highest flux of $22.2 \mathrm{~kg} / \mathrm{m}^{2} \mathrm{~h}$ at a temperature of $65 \pm 1{ }^{\circ} \mathrm{C}$, whereas the lowest flux at the same temperature was $11.9 \mathrm{~kg} / \mathrm{m}^{2} \mathrm{~h}$ for pure $\mathrm{PcH}$ membrane. Adding CNTs into $\mathrm{PcH}$ resulted in enhancing the permeate flux by $43 \%$. Compared to the $\mathrm{PcH}$ membrane, triple-layer nanocomposite $\mathrm{PcH}-\mathrm{PES}-\mathrm{PcH} / \mathrm{CNTs}$ membrane showed $83 \%$ higher permeation flux. Considering the similar contact angle and LEP for PcH and triple-layer nanocomposite PcH-PES-PcH/CNTs membranes, the higher porosity of the triple-layer membrane looks to be the effective parameter of the membrane, which affects the MD performance. As can be seen in Figure 9, the salt rejection for the triple layer membrane was almost $100 \%$ which means that the permeated water was almost pure. 


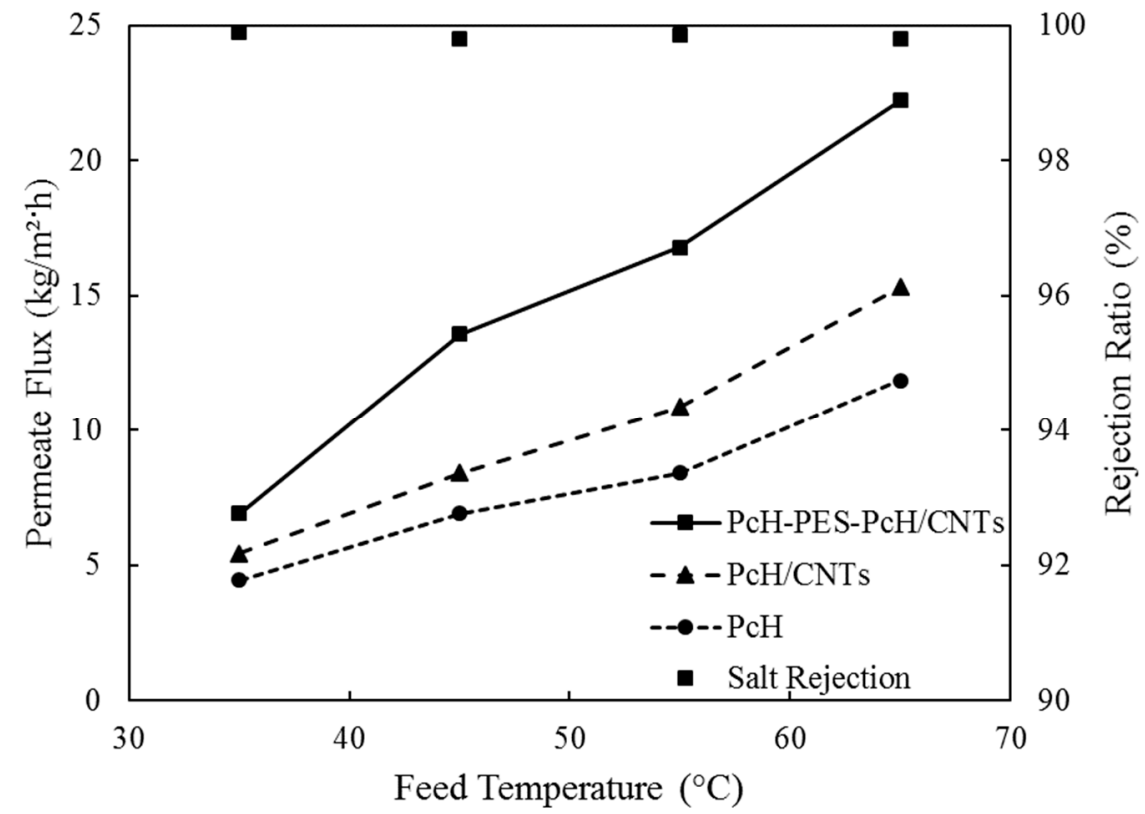

Figure 9. Permeate flux vs. feed water temperature for different membranes.

\subsubsection{Effect of Feed Water Flow Rate}

The effect of the feedwater flow rate on the membrane flux and the salt rejection was studied, and the results were shown in Figure 10. The feed flow rate was varied from 9 to $27 \mathrm{~L} / \mathrm{h}$, Reynolds number increased from around 1650 to 4950, while the feed temperature and salt concentration were kept constant at $65 \pm 1{ }^{\circ} \mathrm{C}$ and $10,000 \mathrm{ppm}$, respectively. As the feed flow rate increased, the permeate flux increased for all the membranes, $\mathrm{PcH}, \mathrm{PcH} / \mathrm{CNTs}$, and triple-layer nanocomposite $\mathrm{PcH}-\mathrm{PES}-\mathrm{PcH} / \mathrm{CNTs}$. At the lowest feed flow rate of $9 \mathrm{~L} / \mathrm{h}$, the membranes permeation flux was almost identical, since, at low flow rates, the boundary layer effects were predominant. However, at higher flow rates, thus, the boundary layer and temperature polarization effects were reduced due to the turbulence effect [58], and consequently, membrane permeation flux increased for all membranes. A significant enhancement for the triple-layer nanocomposite PcH-PES-PcH/CNTs (164\% improvement) is completely clear from Figure 10. It is worth explaining that within the range of the flow rate studied ( 9 to $27 \mathrm{~L} / \mathrm{h}$ ), the salt rejection decreased from $99.9 \%$ to $99.3 \%$, which indicates that the change in salt rejection was marginal.

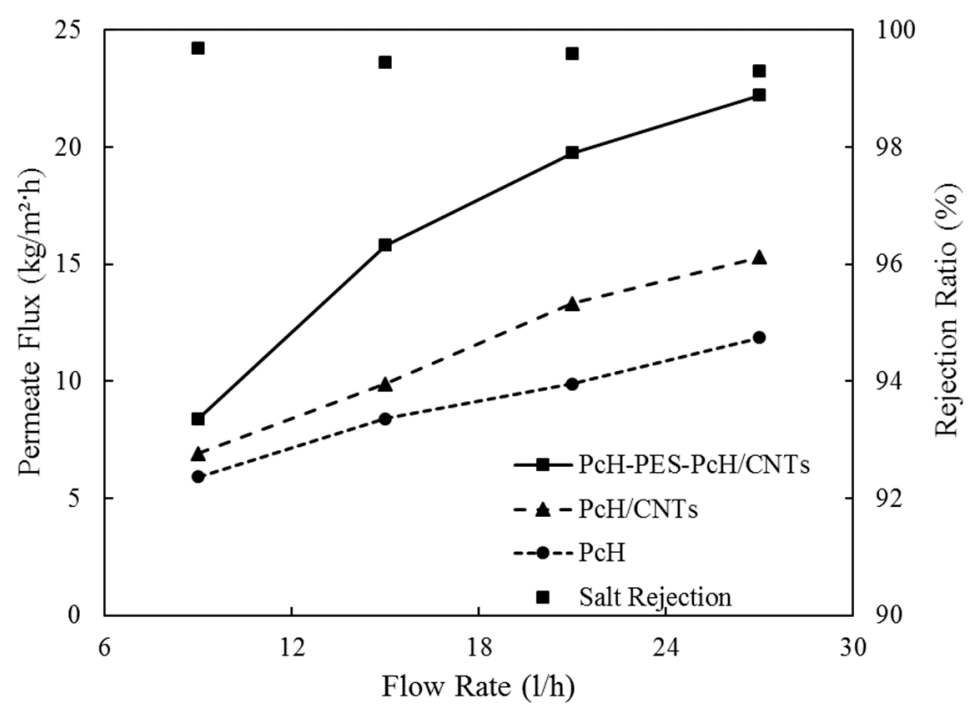

Figure 10. Permeate flux vs. feedwater flow rate for different membranes. 


\subsubsection{Effect of Salt Concentration}

The effect of salt concentration against permeate flux is shown in Figure 11. Salt concentration varied from 10,000 to 34,000 ppm while the feed temperature and flow rate were kept constant at $65 \pm 1{ }^{\circ} \mathrm{C}$ and $27 \mathrm{~L} / \mathrm{h}$, respectively. At high feed salt concentration, concentration polarization plays a significant role [59], where a thicker boundary layer reduces the mass transfer driving force. For PcH/CNTs membrane, the permeation flux decreased from $15.3 \mathrm{~kg} / \mathrm{m}^{2} \mathrm{~h}$ at $10,000 \mathrm{ppm}$ to $5.4 \mathrm{~kg} / \mathrm{m}^{2} \mathrm{~h}$ (about $64.7 \%$ reduction) at 34,000 ppm, while the flux of PcH-PES-PcH/CNTs triple-layer nanocomposite membrane was reduced from $22.2 \mathrm{~kg} / \mathrm{m}^{2} \mathrm{~h}$ to $8.4 \mathrm{~kg} / \mathrm{m}^{2} \mathrm{~h}(61.8 \%$ reduction). As it is clear from Figure 11 , at $34,000 \mathrm{ppm}$, permeation fluxes of the different evaluated membranes are almost the same. It means that at high salt concentrations, it seems that the effect of the membrane material is negligible. We hypothesized that this reduction in flux at a high salt concentration of feed could be attributed to the salt crystallization on the membrane surface, as shown in Figure 12. Indeed, the membrane flux can be recovered by washing the membrane to remove scales from it.

Although not shown here, the triple-layer PcH-PES-PcH/CNTs nanocomposite membrane showed slightly lower salt rejection than that of the $\mathrm{PcH} / \mathrm{CNTs}$ membrane (98.7 and $99.9 \%$ salt, respectively) at $34,000 \mathrm{ppm}$ feed salt concentration. This tiny difference in salt rejection may be attributed to the higher porosity of the PcH-PES-PcH/CNTs composite membrane that showed much higher permeation flux at the same conditions than the PcH/CNTs membrane as previously showed.

To have a better understanding of the MD performance of the prepared membranes, the permeation flux is compared with those reported in previously published literature with similar conditions. The comparisons are summarized in Table 3. The prepared triple-layer PcH-PES-PcH/CNTs composite membrane showed comparable characteristics that make it a promising candidate for the MD desalination process. It is clear from Table 3 that permeation fluxes of $\mathrm{PcH}$ or composites of $\mathrm{PcH}$ and PVDF membranes were less than $7 \mathrm{~kg} / \mathrm{m}^{2} \mathrm{~h}$. The triple layer of nanocomposite PcH-PES-PcH/CNTs membrane used in this study showed that the minimum permeation flux was around $8.4 \mathrm{~kg} / \mathrm{m}^{2} \mathrm{~h}$, and the maximum one was $22.2 \mathrm{~kg} / \mathrm{m}^{2} \mathrm{~h}$. We strongly believe that this increment in MD membrane performance is related to the presence of the middle layer PES with CNTs that had high porosity. Thus, it can be concluded that the newly developed triple-layer PcH-PES-PcH/CNTs composite membrane is appropriate for MD applications.

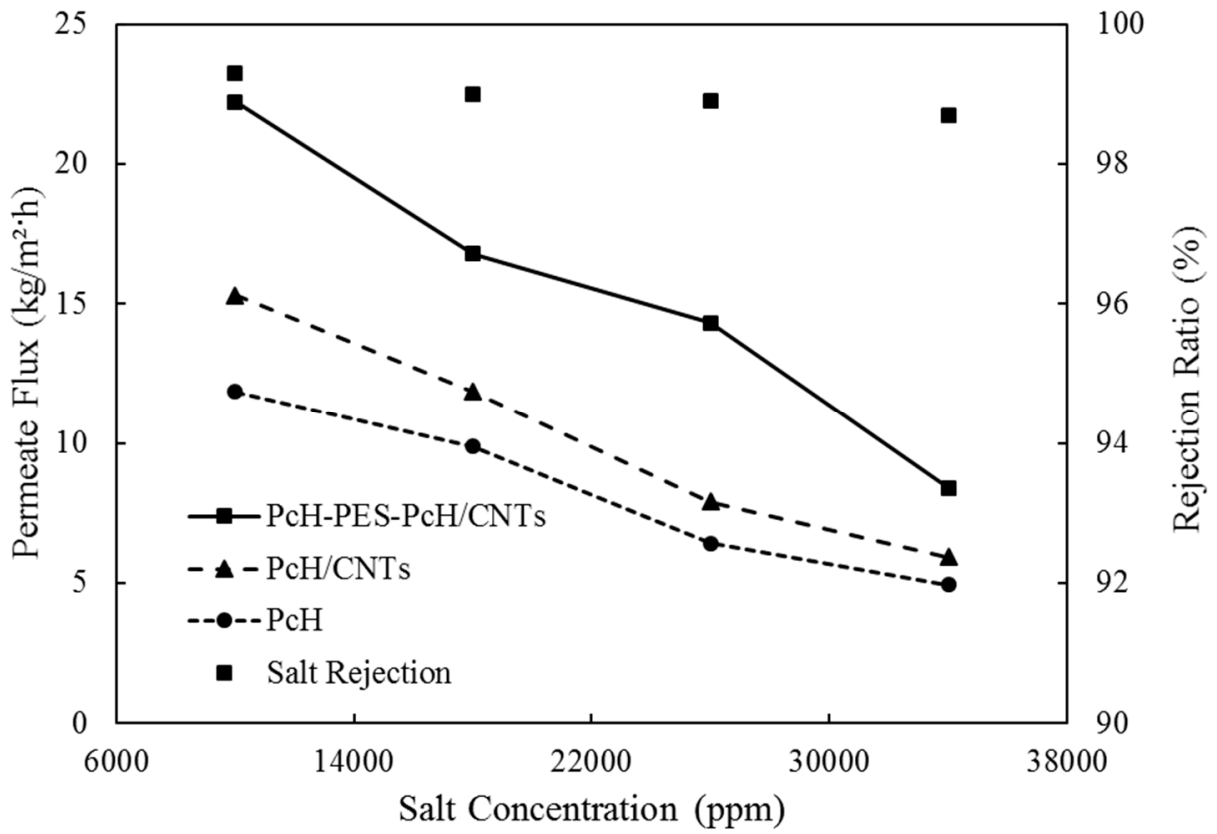

Figure 11. Permeate flux vs. feed salt concentration for different membranes. 

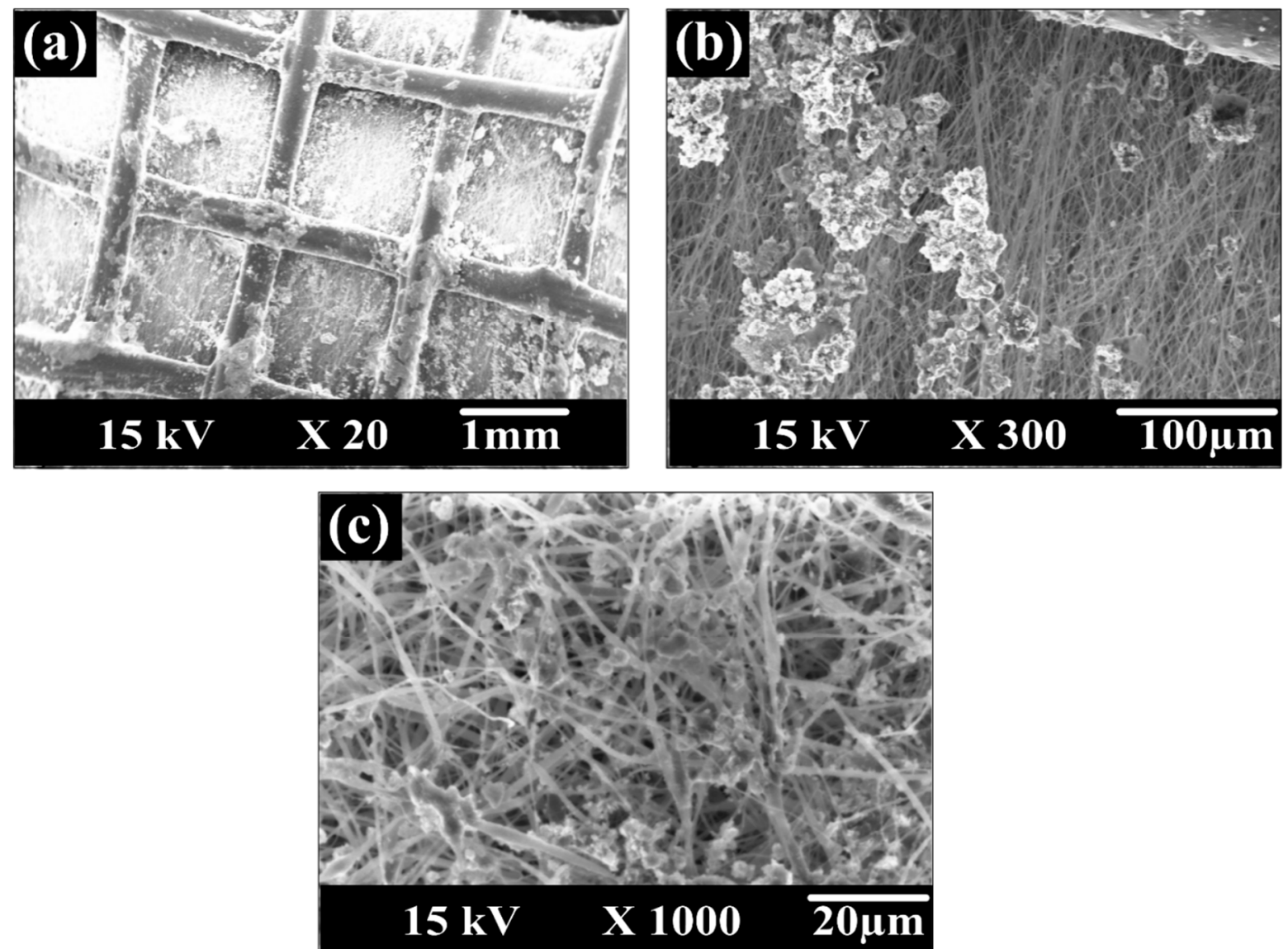

Figure 12. SEM images of the formed scales on (a) the spacer, (b) and (c) PcH-PES-PcH/CNTs nanocomposite membrane fibers, and with higher magnifications.

Table 3. Characteristics and performance of the fabricated PcH-PES-PcH/CNTs composite membrane in this study compared to those of previously reported membranes.

\begin{tabular}{|c|c|c|c|c|c|c|}
\hline Polymer & $\begin{array}{c}\text { Membrane } \\
\text { Characteristics }\end{array}$ & Feed Concen. & $\begin{array}{l}\mathrm{T}_{\text {feed }} \\
\left({ }^{\circ} \mathrm{C}\right)\end{array}$ & $\begin{array}{c}\text { Temperature } \\
\left({ }^{\circ} \mathrm{C}\right)\end{array}$ & $\underset{\substack{\text { Flux } \\
\left(\mathrm{kg} / \mathrm{m}^{2} \mathrm{~h}\right)}}{ }$ & Ref. \\
\hline $\begin{array}{l}\text { Silica-PVDF composite, } \\
\text { electrospinning }\end{array}$ & Contact angle $156.3^{\circ}$ & 3.5 wt. $\% \mathrm{NaCl}$ & 60 & 20 & 18.1 & [17] \\
\hline PcH-CNTs & Contact angle $91.65^{\circ}$ & $3 \mathrm{wt} . \%$ mixed salts & 74 & 56 & $0.6-1$ & [60] \\
\hline $\begin{array}{l}\text { PVDF-based membranes, } \\
\text { electrospinning }\end{array}$ & Contact angle $128^{\circ}-154^{\circ}$ & $1-3.5$ wt. $\% \mathrm{NaCl}$ & $50-80$ & $17-24$ & 4.28 & [61] \\
\hline $\begin{array}{l}\mathrm{TiO}_{2} \text { and fluoro-silane } \\
\text { compound coating on PTFE }\end{array}$ & $\begin{array}{c}\text { Average pore diameter: } \\
0.25 \mu \mathrm{m}\end{array}$ & Up to $10 \mathrm{wt} . \% \mathrm{NaCl}$ & 60 & 25 & $4-6$ & [62] \\
\hline PVDF-PcH & contact angle: $96.4^{\circ}$ & 5 wt. $\% \mathrm{NaCl}$ solution & 80 & 17 & 9 & [63] \\
\hline $\mathrm{PcH}-\mathrm{CNF}$ & contact angle: $115^{\circ}$ & 3 wt. $\% \mathrm{NaCl}$ & 70 & 20 & 7-8 & {$[64]$} \\
\hline $\begin{array}{l}\text { PcH-PES-PcH/CNTs } \\
\text { composite membrane }\end{array}$ & $\begin{array}{c}\text { Porosity: } 91 \pm 1.8 \% \\
\text { contact angle: } 144^{\circ} \pm 2^{\circ}\end{array}$ & $\begin{array}{c}1-3.5 \text { wt. } \% \\
\mathrm{NaCl} \text { solution }\end{array}$ & $35-65$ & $20-25$ & $8.4-22.2$ & This study \\
\hline
\end{tabular}

\section{Conclusions}

The possibility of utilizing modified PES as a cost-effective membrane bulk material for the MD process was evaluated using the electrospinning method. Triple-layer nanocomposite PcH-PES$\mathrm{PcH} / \mathrm{CNTs}$ and two control $\mathrm{PcH}, \mathrm{PcH} / \mathrm{CNTs}$ membranes were fabricated using the electrospinning method and their performance in a direct contact MD system was investigated. PES/CNTs showed very low LEP that made it very difficult to apply for MD application. Thus, a PES/CNTs layer was sandwiched between two layers of the $\mathrm{PcH} / \mathrm{CNTs}$, which gave very high surface hydrophobicity (water 
contact angle of $144^{\circ} \pm 2^{\circ}$ ) and appropriate LEP suitable for the MD applications. PES/CNTs layer hydrophobicity was close to that of the $\mathrm{PcH}$ and similar to those membranes vastly used for MD in many published papers. Appropriate hydrophobicity of the bulk structure ensures avoiding capillary condensation inside the membrane, which is important for MD applications. Combining both effects of the high surface hydrophobicity and high bulk porosity resulted in a membrane with adequate MD performance. Permeation flux of the triple-layer nanocomposite membrane reached $22.2 \mathrm{~kg} / \mathrm{m}^{2} \mathrm{~h}$ with a salt rejection of $99.3 \%$ at $27 \mathrm{~L} / \mathrm{h}$ feed flow rate, $65 \pm 1{ }^{\circ} \mathrm{C}$ feed temperature, and $10000 \mathrm{ppm}$ salt concentration. This novel three-layer PcH-PES-PcH/CNTs membrane showed superior performance for the MD desalination process with a reasonable cost relative to the other commercial MD membranes.

Author Contributions: Conceptualization, A.H.E.-S., N.N. and M.N.S.; methodology, M.R.E.; software, M.S.S. and M.A.S.; validation, M.R.E., M.S.S. and M.N.S.; formal analysis, N.N. and M.N.S.; writing-original draft preparation, M.R.E. and M.N.S.; writing — review and editing, N.N. and S.R.; supervision, A.H.E.-S. and H.M. All authors have read and agreed to the published version of the manuscript.

Funding: This research received no external funding.

Acknowledgments: The authors would like to appreciate the support of the Egypt-Japan University of Science and Technology (E-JUST) by allowing the fabrication of the MD cell inside the University workshops.

Conflicts of Interest: The authors declare no conflict of interest.

\section{References}

1. Acevedo, L.; Uche, J.; Del-Amo, A.J.W. Improving the distillate prediction of a membrane distillation unit in a trigeneration scheme by using artificial neural networks. Water 2018, 10, 310. [CrossRef]

2. Rosegrant, M.W.; Cai, X.; Cline, S.A. Global Water Outlook to 2025; International Water Management Institute: Colombo, Sri Lanka, 2002.

3. Alkhudhiri, A.; Darwish, N.; Hilal, N.J.D. Membrane distillation: A comprehensive review. Desalination 2012, 287, 2-18. [CrossRef]

4. Drioli, E.; Ali, A.; Macedonio, F.J.D. Membrane distillation: Recent developments and perspectives. Desalination 2015, 356, 56-84. [CrossRef]

5. Khayet, M.; García-Payo, M.C.; García-Fernández, L.; Contreras-Martínez, J. Dual-layered electrospun nanofibrous membranes for membrane distillation. Desalination 2018, 426, 174-184. [CrossRef]

6. Greenlee, L.F.; Lawler, D.F.; Freeman, B.D.; Marrot, B.; Moulin, P.J.W. Reverse osmosis desalination: Water sources, technology, and today's challenges. Water Res. 2009, 43, 2317-2348. [CrossRef]

7. Filippini, G.; Al-Obaidi, M.; Manenti, F.; Mujtaba, I.M.J.D. Performance analysis of hybrid system of multi effect distillation and reverse osmosis for seawater desalination via modelling and simulation. Desalination 2018, 448, 21-35. [CrossRef]

8. El-Shazly, A.; Al-Zahrani, A.; Alhamed, Y.; Nosier, S.J.D. Productivity intensification of humidificationDehumidification desalination unit by using pulsed water flow regime. Desalination 2012, 293, 53-60. [CrossRef]

9. Jeon, S.; Rajabzadeh, S.; Okamura, R.; Ishigami, T.; Hasegawa, S.; Kato, N.; Matsuyama, H.J.W. The effect of membrane material and surface pore size on the fouling properties of submerged membranes. Water 2016, 8 , 602. [CrossRef]

10. Mi, B.; Elimelech, M.J.J. Organic fouling of forward osmosis membranes: Fouling reversibility and cleaning without chemical reagents. J. Membr. Sci. 2010, 348, 337-345. [CrossRef]

11. Tijing, L.D.; Woo, Y.C.; Choi, J.-S.; Lee, S.; Kim, S.-H.; Shon, H.K. Fouling and its control in membrane distillation-A review. J. Membr. Sci. 2015, 475, 215-244. [CrossRef]

12. Alklaibi, A.M.; Lior, N.J.D. Membrane-distillation desalination: Status and potential. Desalination 2005, 171, 111-131. [CrossRef]

13. Camacho, L.M.; Dumée, L.; Zhang, J.; Li, J.-D.; Duke, M.; Gomez, J.; Gray, S.J.W. Advances in membrane distillation for water desalination and purification applications. Water 2013, 5, 94-196. [CrossRef]

14. Khayet, M.J. Membranes and theoretical modeling of membrane distillation: A review. Adv. Colloid Interface Sci. 2011, 164, 56-88. [CrossRef] 
15. Salem, M.S.; El-shazly, A.H.; Nady, N.; Elmarghany, M.R.; Shouman, M.A.; Sabry, M.N. 3-D numerical investigation on commercial PTFE membranes for membrane distillation: Effect of inlet conditions on heat and mass transfer. Case Stud. Therm. Eng. 2019, 13, 100396. [CrossRef]

16. Bonyadi, S.; Chung, T.S. Flux enhancement in membrane distillation by fabrication of dual layer hydrophilic-Hydrophobic hollow fiber membranes. J. Membr. Sci. 2007, 306, 134-146. [CrossRef]

17. Liao, Y.; Loh, C.-H.; Wang, R.; Fane, A.G. Electrospun superhydrophobic membranes with unique structures for membrane distillation. ACS Appl. Mater. Interfaces 2014, 6, 16035-16048. [CrossRef]

18. Qtaishat, M.; Khayet, M.; Matsuura, T.J. Novel porous composite hydrophobic/hydrophilic polysulfone membranes for desalination by direct contact membrane distillation. J. Membr. Sci. 2009, 341, 139-148. [CrossRef]

19. El-Marghany, M.R.; El-Shazly, A.H.; Salem, M.S.A.; Sabry, M.N.; Nady, N. Novel Membrane Suitable for Membrane Distillation: Effect of Mixed Nanofillers on the Membrane Performance. Key Eng. Mater. 2019, 801, 325-330. [CrossRef]

20. Salem, M.S.A.; El-Shazly, A.H.; El-Marghany, M.R.; Sabry, M.N.; Nady, N. Effect of Adding Functionalized Graphene on the Performance of PVDF Membrane in Direct Contact Membrane Distillation. Key Eng. Mater. 2019, 801, 337-342. [CrossRef]

21. Ma, L.; Dong, X.; Chen, M.; Zhu, L.; Wang, C.; Yang, F.; Dong, Y.J.M. Fabrication and water treatment application of carbon nanotubes (CNTs)-based composite membranes: A review. Membranes 2017, 7, 16. [CrossRef]

22. Ashraf, A.; Salih, H.; Nam, S.; Dastgheib, S.A.J.C. Robust carbon nanotube membranes directly grown on Hastelloy substrates and their potential application for membrane distillation. Carbon 2016, 106, 243-251. [CrossRef]

23. Nasrabadi, A.T.; Foroutan, M.J.D. Ion-separation and water-purification using single-walled carbon nanotube electrodes. Desalination 2011, 277, 236-243. [CrossRef]

24. Chowdhury, Z.Z.; Sagadevan, S.; Johan, R.B.; Shah, S.T.; Adebesi, A.; Md, S.I.; Rafique, R.F. A review on electrochemically modified carbon nanotubes (CNTs) membrane for desalination and purification of water. Mater. Res. Express 2018, 5, 102001. [CrossRef]

25. Yan, K.-K.; Jiao, L.; Lin, S.; Ji, X.; Lu, Y.; Zhang, L.J.D. Superhydrophobic electrospun nanofiber membrane coated by carbon nanotubes network for membrane distillation. Desalination 2018, 437, 26-33. [CrossRef]

26. Das, R.; Ali, M.E.; Hamid, S.B.A.; Ramakrishna, S.; Chowdhury, Z.Z. Carbon nanotube membranes for water purification: A bright future in water desalination. Desalination 2014, 336, 97-109. [CrossRef]

27. Leaper, S.; Abdel-Karim, A.; Faki, B.; Luque-Alled, J.M.; Alberto, M.; Vijayaraghavan, A.; Holmes, S.M.; Szekely, G.; Badawy, M.I.; Shokri, N.J. Flux-enhanced PVDF mixed matrix membranes incorporating APTS-functionalized graphene oxide for membrane distillation. J. Membr. Sci. 2018, 554, 309-323. [CrossRef]

28. Ragunath, S.; Roy, S.; Mitra, S. Carbon nanotube immobilized membrane with controlled nanotube incorporation via phase inversion polymerization for membrane distillation based desalination. Sep. Purif. Technol. 2018, 194, 249-255. [CrossRef]

29. Roy, S.; Bhadra, M.; Mitra, S. Enhanced desalination via functionalized carbon nanotube immobilized membrane in direct contact membrane distillation. Sep. Purif. Technol. 2014, 136, 58-65. [CrossRef]

30. Bhadra, M.; Roy, S.; Mitra, S. Flux enhancement in direct contact membrane distillation by implementing carbon nanotube immobilized PTFE membrane. Sep. Purif. Technol. 2016, 161, 136-143. [CrossRef]

31. Salem, M.S.; El-Shazly, A.H.; Nady, N.; Elmarghany, M.R.; Sabry, M.N. PES/PVDF blend membrane and its composite with graphene nanoplates: Preparation, characterization, and water desalination via membrane distillation. Desalin. Water Treat. 2019, 166, 9-23. [CrossRef]

32. Woo, Y.C.; Tijing, L.D.; Shim, W.-G.; Choi, J.-S.; Kim, S.-H.; He, T.; Drioli, E.; Shon, H.K. Water desalination using graphene-enhanced electrospun nanofiber membrane via air gap membrane distillation. J. Membr. Sci. 2016, 520, 99-110. [CrossRef]

33. Lee, E.-J.; An, A.K.; Hadi, P.; Lee, S.; Woo, Y.C.; Shon, H.K. Advanced multi-nozzle electrospun functionalized titanium dioxide/polyvinylidene fluoride-co-hexafluoropropylene $\left(\mathrm{TiO}_{2} / \mathrm{PVDF}-\mathrm{HFP}\right)$ composite membranes for direct contact membrane distillation. J. Membr. Sci. 2017, 524, 712-720. [CrossRef]

34. Wang, J.; Zheng, L.; Wu, Z.; Zhang, Y.; Zhang, X.J. Fabrication of hydrophobic flat sheet and hollow fiber membranes from PVDF and PVDF-CTFE for membrane distillation. J. Membr. Sci. 2016, 497, 183-193. [CrossRef] 
35. Van der Veen, S.; Nady, N.; Franssen, M.C.; Zuilhof, H.; Boom, R.M.; Abee, T.; Schroën, K.J. Listeria monocytogenes repellence by enzymatically modified PES surfaces. J. Appl. Polym. 2015, 132. [CrossRef]

36. Nady, N.; Franssen, M.; Zuilhof, H.; Boom, R.; Schroën, K.J.W. Enzymatic modification of polyethersulfone membranes. Water 2012, 4, 932-943. [CrossRef]

37. Yoon, K.; Hsiao, B.S.; Chu, B. Formation of functional polyethersulfone electrospun membrane for water purification by mixed solvent and oxidation processes. Polymer 2009, 50, 2893-2899. [CrossRef]

38. Liu, Y.; Su, Y.; Zhao, X.; Li, Y.; Zhang, R.; Jiang, Z. Improved antifouling properties of polyethersulfone membrane by blending the amphiphilic surface modifier with crosslinked hydrophobic segments. J. Membr. Sci. 2015, 486, 195-206. [CrossRef]

39. Nady, N.J.M. PES surface modification using green chemistry: New generation of antifouling membranes. Membranes 2016, 6, 23. [CrossRef]

40. Abdallah, H.; Moustafa, A.F.; AlAnezi, A.A.; El-Sayed, H.E.M. Performance of a newly developed titanium oxide nanotubes/polyethersulfone blend membrane for water desalination using vacuum membrane distillation. Desalination 2014, 346, 30-36. [CrossRef]

41. Hou, D.; Lin, D.; Ding, C.; Wang, D.; Wang, J. Fabrication and characterization of electrospun superhydrophobic PVDF-HFP/SiNPs hybrid membrane for membrane distillation. Sep. Purif. Technol. 2017, 189, 82-89. [CrossRef]

42. Arribas, P.; Khayet, M.; García-Payo, M.C.; Gil, L. Self-sustained electro-spun polysulfone nano-fibrous membranes and their surface modification by interfacial polymerization for micro- and ultra-filtration. Sep. Purif. Technol. 2014, 138, 118-129. [CrossRef]

43. An, A.K.; Guo, J.; Lee, E.-J.; Jeong, S.; Zhao, Y.; Wang, Z.; Leiknes, T. PDMS/PVDF hybrid electrospun membrane with superhydrophobic property and drop impact dynamics for dyeing wastewater treatment using membrane distillation. J. Membr. Sci. 2017, 525, 57-67. [CrossRef]

44. Elmarghany, M.R.; El-Shazly, A.H.; Salem, M.S.; Sabry, M.N.; Nady, N. Thermal analysis evaluation of direct contact membrane distillation system. Case Stud. Therm. Eng. 2019, 13, 100377. [CrossRef]

45. Essalhi, M.; Khayet, M. Self-sustained webs of polyvinylidene fluoride electrospun nanofibers at different electrospinning times: 1 . Desalination by direct contact membrane distillation. J. Membr. Sci. 2013, 433, 167-179. [CrossRef]

46. Lalia, B.S.; Guillen-Burrieza, E.; Arafat, H.A.; Hashaikeh, R. Fabrication and characterization of polyvinylidenefluoride-co-hexafluoropropylene (PVDF-HFP) electrospun membranes for direct contact membrane distillation. J. Membr. Sci. 2013, 428, 104-115. [CrossRef]

47. Ke, H.; Feldman, E.; Guzman, P.; Cole, J.; Wei, Q.; Chu, B.; Alkhudhiri, A.; Alrasheed, R.; Hsiao, B.S. Electrospun polystyrene nanofibrous membranes for direct contact membrane distillation. J. Membr. Sci. 2016, 515, 86-97. [CrossRef]

48. Rahimpour, A.; Madaeni, S.S.; Mansourpanah, Y. Fabrication of polyethersulfone (PES) membranes with nano-porous surface using potassium perchlorate $(\mathrm{KClO} 4)$ as an additive in the casting solution. Desalination 2010, 258, 79-86. [CrossRef]

49. Eykens, L.; De Sitter, K.; Stoops, L.; Dotremont, C.; Pinoy, L.; Van der Bruggen, B. Development of polyethersulfone phase-inversion membranes for membrane distillation using oleophobic coatings. J. Appl. Polym. Sci. 2017, 134, 45516. [CrossRef]

50. Rastegarpanah, A.; Mortaheb, H.R. Surface treatment of polyethersulfone membranes for applying in desalination by direct contact membrane distillation. Desalination 2016, 377, 99-107. [CrossRef]

51. Carlos Mierzwa, J.; Vecitis, C.D.; Carvalho, J.; Arieta, V.; Verlage, M. Anion dopant effects on the structure and performance of polyethersulfone membranes. J. Membr. Sci. 2012, 421-422, 91-102. [CrossRef]

52. Islam, M.S.; McCutcheon, J.R.; Rahaman, M.S. A high flux polyvinyl acetate-coated electrospun nylon $6 / \mathrm{SiO}_{2}$ composite microfiltration membrane for the separation of oil-in-water emulsion with improved antifouling performance. J. Membr. Sci. 2017, 537, 297-309. [CrossRef]

53. Luong, J.H.; Hrapovic, S.; Wang, D.; Bensebaa, F.; Simard, B.J. Solubilization of Multiwall Carbon Nanotubes by 3-Aminopropyltriethoxysilane Towards the Fabrication of Electrochemical Biosensors with Promoted Electron Transfer. Electroanalysis 2004, 16, 132-139. [CrossRef]

54. Rodgers, R.; Hill, G.J. Equations for vapour pressure versus temperature: Derivation and use of the Antoine equation on a hand-held programmable calculator. Br. J. Anaesth. 1978, 50, 415-424. [CrossRef] [PubMed]

55. Wenzel, R.N. Resistance of solid surfaces to wetting by water. Ind. Eng. Chem. Res. 1936, 28, 988-994. [CrossRef] 
56. Rezaei, M.; Warsinger, D.M.; Duke, M.C.; Matsuura, T.; Samhaber, W.M. Wetting phenomena in membrane distillation: Mechanisms, reversal, and prevention. Water Res. 2018, 139, 329-352. [CrossRef]

57. Souhaimi, M.K.; Matsuura, T. Membrane Distillation: Principles and Applications; Elsevier: Amsterdam, The Netherlands, 2011.

58. Khalifa, A.; Ahmad, H.; Antar, M.; Laoui, T.; Khayet, M.J.D. Experimental and theoretical investigations on water desalination using direct contact membrane distillation. Desalination 2017, 404, 22-34. [CrossRef]

59. Gethard, K.; Sae-Khow, O.; Mitra, S. Water Desalination Using Carbon-Nanotube-Enhanced Membrane Distillation. ACS Appl. Mater. Interfaces 2011, 3, 110-114. [CrossRef]

60. Balis, E.; Sapalidis, A.; Pilatos, G.; Kouvelos, E.; Athanasekou, C.; Veziri, C.; Boutikos, P.; Beltsios, K.; Romanos, G.J. Enhancement of vapor flux and salt rejection efficiency induced by low cost-high purity MWCNTs in upscaled PVDF and PVDF-HFP hollow fiber modules for membrane distillation. Sep. Purif. Technol. 2019, 224, 163-179. [CrossRef]

61. Tang, N.; Feng, C.; Han, H.; Hua, X.; Zhang, L.; Xiang, J.; Cheng, P.; Du, W.; Wang, X.J.D. High permeation flux polypropylene/ethylene vinyl acetate co-blending membranes via thermally induced phase separation for vacuum membrane distillation desalination. Desalination 2016, 394, 44-55. [CrossRef]

62. Meng, S.; Ye, Y.; Mansouri, J.; Chen, V.J. Crystallization behavior of salts during membrane distillation with hydrophobic and superhydrophobic capillary membranes. J. Membr. Sci. 2015, 473, 165-176. [CrossRef]

63. Wu, P.; Jiang, L.Y.; Hu, B.J. Fabrication of novel PVDF/P (VDF-co-HFP) blend hollow fiber membranes for DCMD. J. Membr. Sci. 2018, 566, 442-454. [CrossRef]

64. Ray, S.S.; Deb, C.K.; Chang, H.M.; Chen, S.S.; Ganesapillai, M.J. Crosslinked PVDF-HFP-based hydrophobic membranes incorporated with CNF for enhanced stability and permeability in membrane distillation. J. Appl. Polym. 2019, 136, 48021. [CrossRef]

(C) 2020 by the authors. Licensee MDPI, Basel, Switzerland. This article is an open access article distributed under the terms and conditions of the Creative Commons Attribution (CC BY) license (http://creativecommons.org/licenses/by/4.0/). 